Tohoku J. exp. Med., 1978, 124, 187-196

\title{
The Effect of Oral Chenodeoxycholic Acid on Cholesterol Solubility in Hepatic Bile
}

\author{
Takashi Matsushiro, Nobuyuki Kobayashi, Noriyoshi \\ Suzuki, Hidemi Yamauchi and Toshio Sato \\ Department of Surgery, Tohoku University School of Medicine, \\ Sendai 980
}

\begin{abstract}
Matsushiro, T., KobaYashi, N., Suzuki, N., Yamadchi, H. and Sato, T. The Effect of Oral Chenodeoxycholic Acid on Cholesterol Solubility in Hepatic Bile. Tohoku J. exp. Med., 1978, 124 (2), 187-196-By oral administration of chenodeoxycholic acid (CDCA) varying in dose for 7 consecutive days to patients who underwent cholecystectomy with biliary drainage for cholesterol gallstone, the biliary cholesterol dissolubility was studied in pursuit of the optimum dose in CDCA therapy for cholesterol gallstone. The rate of dissolution of biliary cholesterol by CDCA administration was highest in cases of $250 \mathrm{mg} / \mathrm{day}$ in dose, followed by those of $750 \mathrm{mg} / \mathrm{day}$. When the dose was observed from per $\mathrm{kg}$ of body weight, the dissolubility of cholesterol was highest in the case of $6.3 \mathrm{mg} / \mathrm{kg}$, followed by one of $12 \mathrm{mg} / \mathrm{kg}$. Thus, it is presumed that in CDCA therapy for cholesterol gallstone a dose of $250 \mathrm{mg} /$ day is too small and $750 \mathrm{mg} /$ day too large in amount from the viewpoint of its effectiveness. The optimum dose probably lies between $5 \mathrm{mg} / \mathrm{kg}$ and $12 \mathrm{mg} / \mathrm{kg}$. A transient elevation in levels of SGOT and SGPT was observed only in one case treated with $750 \mathrm{mg} / \mathrm{kg}$. medicinal dissolution of gallstone; chenodeoxycholic acid; cholesterol dissolubility
\end{abstract}

Since Danzinger et al. (1972) reported on the dissolution of cholesterol gallstones by oral administration of chenodeoxycholic acid (CDCA), the effect of CDCA in dissolving gallstones has been studied by various researchers, and not a few of clinically successful cases have been reported. But there are very few studies in pursuit of the optimum dose of CDCA for cholesterol dissolubility in bile.

Oral administration of CDCA was made in varying doses for 7 consecutive days in patients, who underwent cholecystectomy with biliary drainage, in order to estimate bile cholesterol dissolubility, and interesting findings were obtained concerning the optimum dose of CDCA.

\section{Materials and Methods}

The subjects examined were 14 patients who underwent cholecystectomy with T-tube drainage for cholesterol gallstone. All these cases proved normal in hepatic function before the operation. The T-tube was cramped two weeks after the operation, and the hepato-intestinal circulation of bile was kept. From the third day after that, CDCA was orally administered for 7 consecutive days in daily doses of $250 \mathrm{mg}, 750 \mathrm{mg}$

Received for publication, July 13, 1977.

This paper is presented in commemoration of the 60th anniversary of the First Department of Surgery, Tohoku University School of Medicine. 
and 1,500 mg. The daily dose of $250 \mathrm{mg}$ was given at one time after morning meal in a group of 7 patients. In the other 7 patients, $250 \mathrm{mg}$ were given three times a day after meals for 7 consecutive days; in 5 of the 7 cases, the daily dose was increased to $1,500 \mathrm{mg}$ on the 8 th day and given consecutively for further 7 days. During the period of CDCA administration, the patients were given the usual diet and received no drugs except digestives. Ten $\mathrm{ml}$ of hepatic bile were sampled daily from the day before the initial CDCA administration through the day of its completion in a fasting state each morning by releasing the T-tube cramp. In the hepatic bile samples, cholesterol, phospholipid and bile acids were measured. On the day before and the 4th and the 8th days after CDCA administration, hepatic function was examined. In other 5 cases without CDCA administration, all these procedures were performed as well to provide control data.

Body weight before the initial CDCA administration ranged from 40 to $65 \mathrm{~kg}$ in patients with a daily dose of $250 \mathrm{mg}$, and from 42 to $63 \mathrm{~kg}$ in those with $750 \mathrm{mg}$ and 1,500 $\mathrm{mg}$. The dose per $\mathrm{kg}$ of body weight ranged from 3.9 to $6.3 \mathrm{mg}$ in cases of $250 \mathrm{mg} / \mathrm{day}$, from 12 to $17.9 \mathrm{mg}$ in those of $750 \mathrm{mg} /$ day, and from 23.8 to $35.7 \mathrm{mg}$ in those of $1,500 \mathrm{mg} /$ day.

Cholesterol in hepatic bile was determined by Leffler's method (Leffler and McDougald 1963), and phospholipid by Bartlett's method (Bartlett 1959), determining lipid-P and calculating the value by $\mathrm{P} \times 25$. Bile acids were measured with gas-liquid chromatography based on Sandberg's method (Sandberg et al. 1965) (Fig. 1). The gas-liquid chromatographic apparatus was Shimazu GC-4 MB type, with a glass column of $1.5 \%$ OV-17 (Nihon Kayaku) $2 \mathrm{~mm}$ in inner diameter and $2 \mathrm{~m}$ in length. The experimental conditions were $265^{\circ} \mathrm{C}$ in column temperature, $275^{\circ} \mathrm{C}$ in detector temperature, $2 \mathrm{~kg} / \mathrm{cm}^{2}$ in carrier gas nitrogen pressure, $50 \mathrm{ml} / \mathrm{min}$ in flow rate, $0.6 \mathrm{~kg} / \mathrm{cm}^{2}$ in hydrogen pressure, and $0.8 \mathrm{~kg} / \mathrm{cm}^{2}$ in air pressure. Used as the standard substance was $5 \alpha$-cholestane. Bile acids determined by a Shimazu integrator ITG-4A revealed their peaks as shown in Fig. 2.

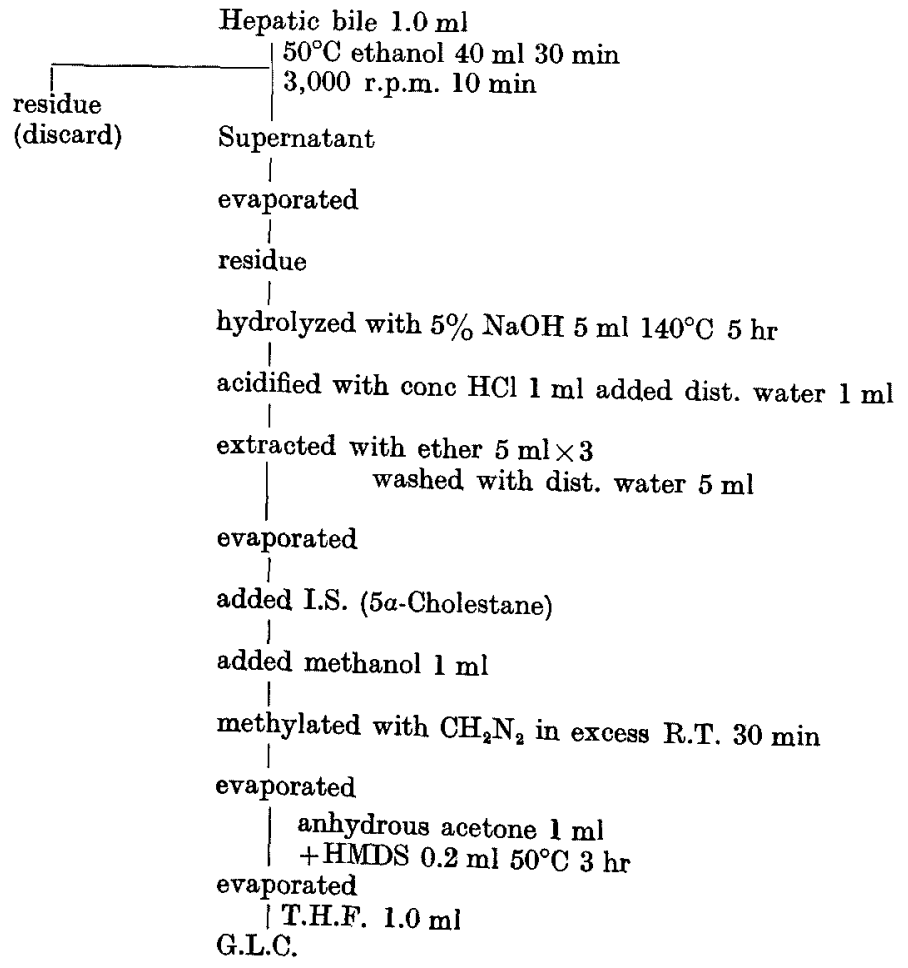

Fig. 1. Analytical method of bile acids. 


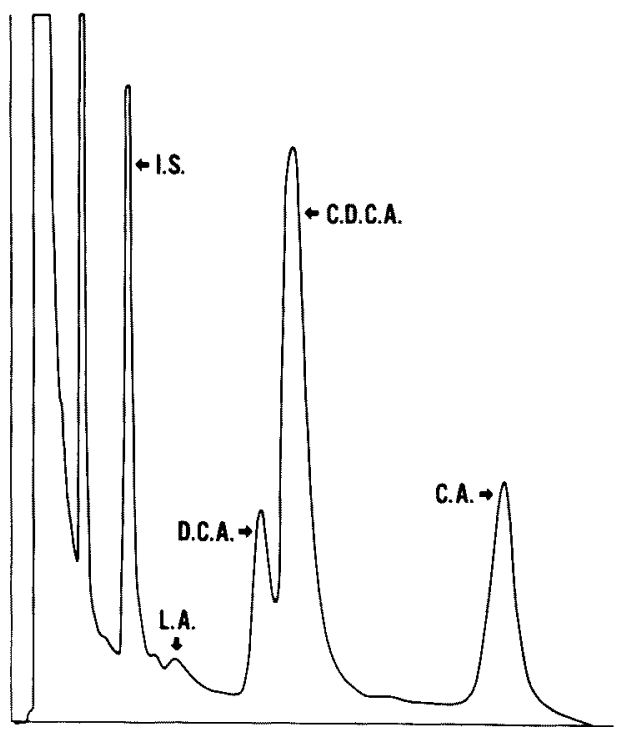

Fig. 2. Gas-liquid chromatogram of bile acid.

LA, Lithocholic acid; DCA, Desoxycholic acid; CA, Cholie acid.

\section{RESULTS}

\section{Changes in bile components}

The mean values of cholesterol content in bile on the day before the initial CDCA administration were $177.4 \pm 20.1 \mathrm{mg} / 100 \mathrm{ml}$ in cases of $250 \mathrm{mg} / \mathrm{day}$, and $181.5 \pm 80.5 \mathrm{mg} / 100 \mathrm{ml}$ in cases of $750 \mathrm{mg} /$ day, both showing no noticeable difference as compared with the control, $199.2 \pm 61.7 \mathrm{mg} / 100 \mathrm{ml}$. Fig. 3 shows daily changes in cholesterol content following CDCA dminaistration, indicated by percentage to the pre-administration level. The control cases without CDCA administration indicated little daily changes in cholesterol content. This trend was similarly

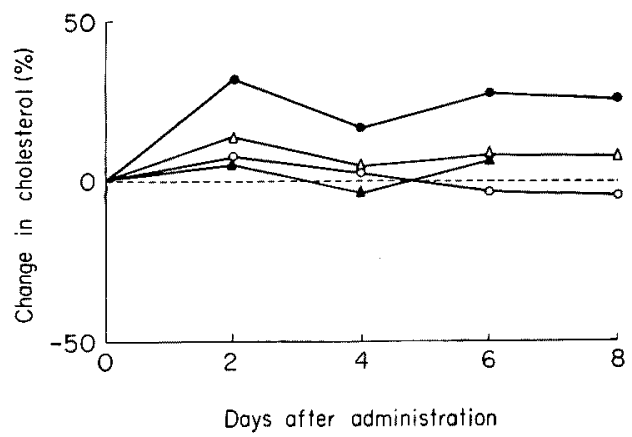

Fig. 3. Changes in cholesterol content of hepatic bile following oral administration of CDCA. Figure shows percent of the pre-administration level. In Figs. 3-7: $0-0$, control; $\Delta \longrightarrow \Delta, 250 \mathrm{mg}$ of CDCA; $\triangle, 750 \mathrm{mg}$ of CDCA; $-\bullet, 1500 \mathrm{mg}$ of CDCA. 
observed in both groups with $250 \mathrm{mg} /$ day and $750 \mathrm{mg} /$ day. A tendency of increasing cholesterol was observed in cases of $1,500 \mathrm{mg} /$ day, but the increase rate was less than $30 \%$. There were no statistically significant differences from pre-administration levels in cholesterol content in either groups.

The mean levels of phospholipid in bile before the initial CDCA administration were $339.4 \pm 73.3 \mathrm{mg} / 100 \mathrm{ml}$ in cases of $250 \mathrm{mg} /$ day, $313.7 \pm 107.9 \mathrm{mg} / 100 \mathrm{ml}$ in cases of $750 \mathrm{mg} /$ day, and $341.1 \pm 95.3 \mathrm{mg} / 100 \mathrm{ml}$ in control cases. Daily changes in biliary phospholipid after CDCA administration in different groups are shown in Fig. 4, indicated by percentage to the pre-administration level. Both groups with $250 \mathrm{mg} /$ day and with $1,500 \mathrm{mg} /$ day tended to show an increase of phospholipid levels by $30 \%$ at highest, in contrast with the control group showing up-and-down changes in level by 10 to $20 \%$ But the changes in the levels were not significant compared with pre-administration levels in either group.

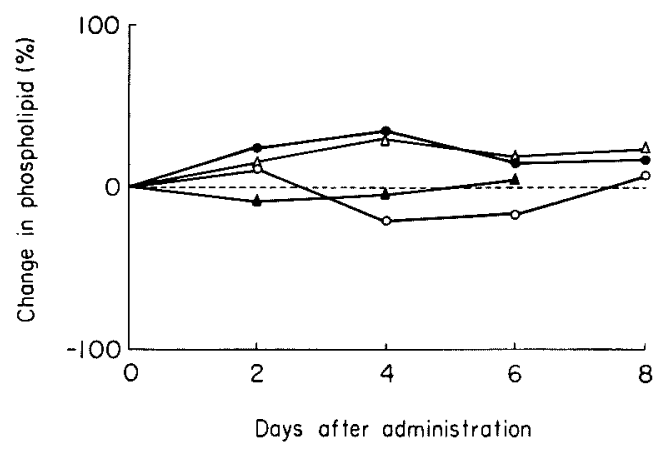

Fig. 4. Changes in phospholipid content of hepatic bile following oral administration of CACA. Figure shows percent of the pre-administration level.

The mean levels of the total bile acids before CDCA administration were $1,076 \pm$ $328.1 \mathrm{mg} / 100 \mathrm{ml}$ in cases of $250 \mathrm{mg} /$ day, $932.9 \pm 360.3 \mathrm{mg} / 100 \mathrm{ml}$ in cases of $750 \mathrm{mg} /$ day, and $890.4 \pm 142.2 \mathrm{mg} / 100 \mathrm{ml}$ in the control. Daily changes in such levels after CDCA administration are shown in Fig. 5. The changes in the level in control cases were less than $20 \%$, while in cases of $250 \mathrm{mg} /$ day and $750 \mathrm{mg} / \mathrm{day}$, the levels were elevated markedly during CDCA administration, with the highest increase rates of $95 \%$ and $65 \%$, respectively. In cases of $1,500 \mathrm{mg} / \mathrm{day}$, the increase rate was less than $40 \%$, showing no significant difference from the preadministration level.

Daily changes in biliary CDCA after CDCA administration are shown by percentage to the pre-administration level in Fig. 6. Although little changes were seen in control cases, the administered groups showed greater increases in the level with larger doses; in the group with $1,500 \mathrm{mg} /$ day, a maximum increase of $200 \%$ was observed. Contrary to biliary CDCA, the levels of cholic acid (CA) after CDCA administration rather tended to fall with an increase in dose (Fig. 7). The control group showed no appreciable changes in the level, but the group with 250 


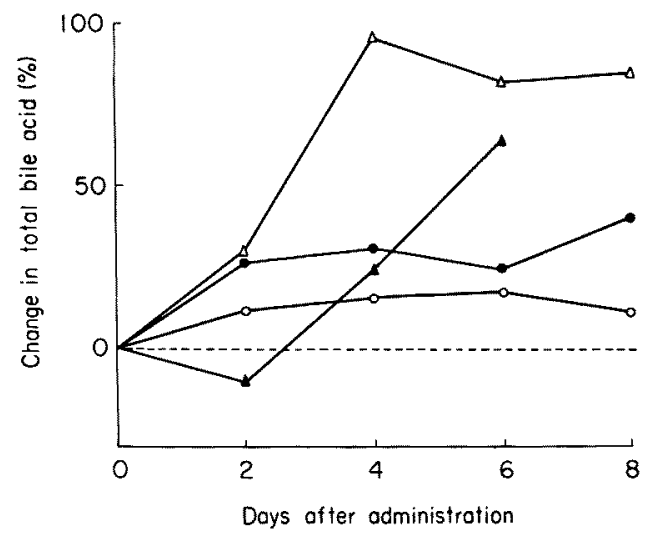

Fig. 5. Changes in total bile acid content of hepatic bile following oral administration of CACA. Figure shows percent of the pre-administration level.

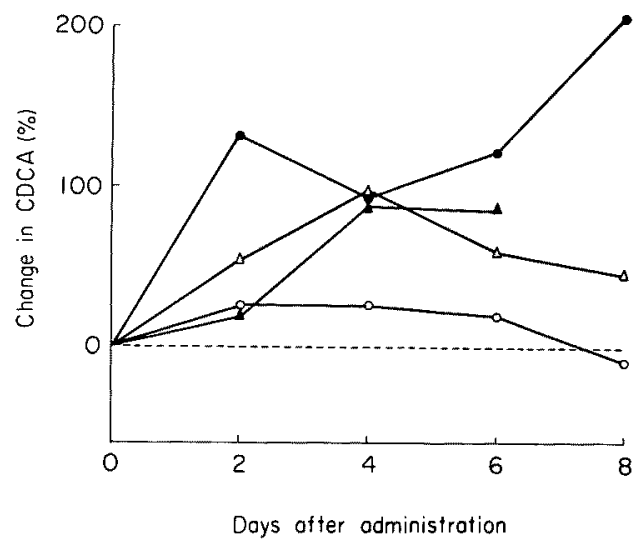

Fig. 6. Changes in CDCA content of hepatic bile following oral administration of CDCA. Figure shows percent of the pre-administration level.

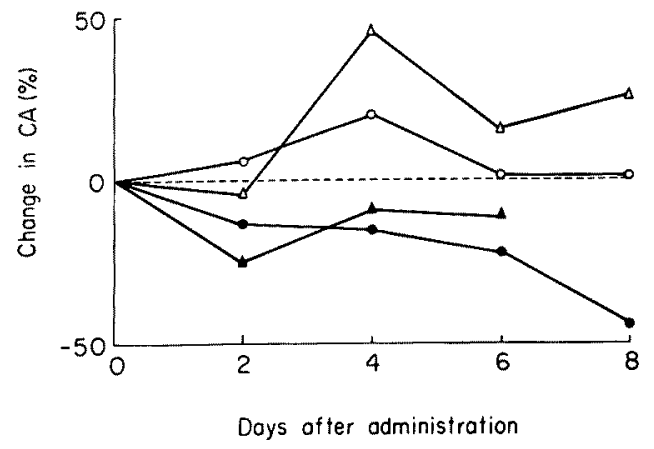

Fig. 7. Chang es in cholic acid (CA) content of hepatic bile following oral administration of CDCA. Figure shows percent of the pre-administration level. 
TaBls 1. Changes in $(B+P) / C$ of hepatic bile following oral administration of $C D C A$

\begin{tabular}{|c|c|c|c|c|c|}
\hline \multirow{3}{*}{ Groups } & \multicolumn{5}{|c|}{$(B+P) / C$ values } \\
\hline & \multirow{2}{*}{$\begin{array}{l}\text { Pre-admin } \\
\text { istration }\end{array}$} & \multicolumn{4}{|c|}{ Days after administration } \\
\hline & & 2nd & 4 th & 6 th & 8 th \\
\hline Control & $6.1 \pm 2.5$ & $\begin{array}{l}7.2 \pm 2.9 \\
\text { N.S. }\end{array}$ & $\begin{array}{l}6.6 \pm 2.2 \\
\text { N.S. }\end{array}$ & $\begin{array}{l}7.5 \pm 3.1 \\
\text { N.S. }\end{array}$ & $\begin{array}{l}6.8 \pm 2.0 \\
\text { N.S. }\end{array}$ \\
\hline $250 \mathrm{mg} / \mathrm{day}$ & $6.0 \pm 0.1$ & $\begin{array}{l}11.0 \pm 4.0 \\
\mathrm{P}<0.05\end{array}$ & $\begin{array}{c}10.4 \pm 2.8 \\
\mathrm{P}<0.05\end{array}$ & $\begin{array}{l}9.6 \pm 1.3 \\
\mathrm{P}<0.05\end{array}$ & $\begin{array}{c}11.5 \pm 7.3 \\
\text { N.S. }\end{array}$ \\
\hline $750 \mathrm{mg} / \mathrm{day}$ & $5.3 \pm 1.8$ & $\begin{array}{l}5.0 \pm 1.6 \\
\text { N.S. }\end{array}$ & $\begin{array}{l}7.7 \pm 1.9 \\
\mathrm{P}<0.05\end{array}$ & $\begin{array}{l}5.8 \pm 2.3 \\
\text { N.S. }\end{array}$ & \\
\hline $1500 \mathrm{mg} / \mathrm{day}$ & $5.3 \pm 1.8$ & $\begin{array}{l}7.4 \pm 0.7 \\
\text { N.S. }\end{array}$ & $\begin{array}{l}7.4 \pm 1.4 \\
\text { N.S. }\end{array}$ & $\begin{array}{c}5.0 \pm 0.9 \\
\text { N.S. }\end{array}$ & $\begin{array}{l}7.4 \pm 2.8 \\
\text { N.S. }\end{array}$ \\
\hline
\end{tabular}

Statistical values were compared with preadministration level. N.S.: not significant.

$\mathrm{mg} /$ day indicated a rising curve of $\mathrm{CA}$ with a maximum of $50 \%$ increase. On the other hand, the cases of $750 \mathrm{mg} /$ day and those of $1,500 \mathrm{mg} /$ day indicated a tendency to decrease biliary CA with increased dosage of CDCA, showing maximum decreases of $25 \%$ and $40 \%$, respectively.

Table 1 shows daily changes in the rate of cholesterol solubility, $(B+P) / C$, (Isakson 1953) and biliary levels of cholesterol $(C)$, phospholipid $(P)$ and total bile acids $(B)$. The means of $(B+P) / C$ in three groups before CDCA administration were 5.3 to 6.0 , showing no distinctive differences from the control level of 6.1. Daily changes in $(B+P) / C$ in the control group showed no significant differences. But in the group with $250 \mathrm{mg} /$ day, the mean level of $(B+P) / C$ was $11.0 \pm 4.0$ on the 2nd day, $10.4 \pm 2.8$ on the 4th day, and $9.6 \pm 1.3$ on the 6 th day, indicating a significant increase as compared with the pre-administration level. A significant increase in $(B+P) / C$ was also found in the group with $750 \mathrm{mg} / \mathrm{day}$ on the 4 th day, but in the group with $1,500 \mathrm{mg} /$ day, no significant difference from the preadministration level was observed.

When CDCA doses were illustrated by per $\mathrm{kg}$ of body weight, elevation in $(B+P) / C$ was comparatively slight in 3 cases of $4.5 \mathrm{mg} / \mathrm{kg}$ or less in the $250 \mathrm{mg} /$ day group, even the highest rate of elevation being only $70 \%$. On the contrary, $(B+P) / C$ increased more than $100 \%$ at highest in the other 4 cases in the same group of $4.6 \mathrm{mg} / \mathrm{kg}$ or more; particularly, one case of the largest dose of $6.3 \mathrm{mg} / \mathrm{kg}$ indicated a $170 \%$ up of $(B+P) / C$ on the 2 nd day and finally reached $230 \%$ rise at maximum. Of 7 cases of $750 \mathrm{mg} /$ day, 3 of $15.0 \mathrm{mg} / \mathrm{kg}$ or less all showed more than $60 \%$ increases in $(B+P) / C$ at highest, and the highest rise of $140 \%$ was observed in a case of the lowest dose of $12 \mathrm{mg} / \mathrm{kg}$ in this group, while the other 4 cases of 15.1 $\mathrm{mg} / \mathrm{kg}$ or more showed almost no signs of increase in $(B+P) / C, 2$ of the 4 cases rather indicating a decreasing tendency of the rate.

Side effects of CDCA administration on hepatic function

Increases in SGOT and SGPT values were demonstrated in only one case of 
increasing dose from $750 \mathrm{mg}$ to $1,500 \mathrm{mg}$. In this case, values of SGOT and SGPT elevated to 105 and $171 \mathrm{U}$ in dose of $750 \mathrm{mg} /$ day, which further elevated to 110 and $303 \mathrm{U}$ in $1,500 \mathrm{mg} /$ day. The lithocholic acid level of $49.2 \mathrm{mg} / 100 \mathrm{ml}$ in dose of 750 $\mathrm{mg} /$ day increased to $202.1 \mathrm{mg} / 100 \mathrm{ml}$ in $1,500 \mathrm{mg} /$ day. On the 7 th day after the cessation of CDCA administration, both SGOT and SGPT returned to normal, showing 15 and $42 \mathrm{U}$, respectively. The dose per $\mathrm{kg}$ of body weight in this case was $16.3 \mathrm{mg} / \mathrm{kg}$ in $750 \mathrm{mg} /$ day. Lithocholic acid was also detected in 2 of 5 control cases and in another case with $750 \mathrm{mg} /$ day. But in the latter case, the level was not elevated with CDCA administration and the hepatic function was normal.

\section{Discussion}

Since chenodeoxycholic acid (CDCA) was noted for its effect in dissolving gallstones, various studies have been done regarding its effective doses, dosing periods, and side effects. However, the optimum dose has not yet been elucidated.

In an effort to throw light on this issue, the present authors orally administered CDCA to clinical cases of cholelithiasis for 7 consecutive days. Using the data of non-administered cases as control, the effects of different doses of CDCA upon biliary cholesterol dissolubility were investigated together with side effects, and the influence on hepatic function was also examined.

Any trend to increasing dissolubility of biliary cholesterol in proportion to doses of CDCA could not be observed. The dissolubility was significantly increased as compared with the preadministration level in cases of $250 \mathrm{mg} /$ day, but not in cases of $1,500 \mathrm{mg} / \mathrm{day}$. Considering the dose per $\mathrm{kg}$ of body weight, elevation in cholesterol dissolubility was notable in cases of $4.6 \mathrm{mg} / \mathrm{kg}$ or more in the group with $250 \mathrm{mg} /$ day and in cases of $15.1 \mathrm{mg} / \mathrm{kg}$ or less in the group with $750 \mathrm{mg} /$ day. The fact that the levels of biliary cholesterol and phospholipid showed no appreciable changes with CDCA administration suggested that elevation in biliary cholesterol dissolubility is attributable to the increase in the total bile acids in bile.

Changes in bile acids in bile with CDCA administration revealed that the level of biliary CDCA elevated in proporition to the doses of CDCA, but that of CA was lowered. This suggests that the increase in the total bile acids is influenced by the changes in the levels of these two bile acids. This trend was also noted by Hofmann and Paumgartner (1974) in their report, showing that increased dose of CDCA induced a proportional increase in $(B+P) / C$ (cholesterol dissolubility) in cases of daily doses of $250 \mathrm{mg}$ and $750 \mathrm{mg}$, but the increase was less in cases of $1,000 \mathrm{mg} /$ day than in those of $750 \mathrm{mg} /$ day. Their report also shows that the level of biliary CDCA became higher with larger doses of CDCA. The disproportion between the dose of CDCA and the changes in biliary bile acids is probably due to the fact that if dosing of some substance is small in amount, it will stimulate the production of the substance and transitorily increase its level, while when the amount is large, it will cause a feed-back system to act and decrease its production. This shows that a dose with maximum stimulation is the most appropriate dose (Small et al. 1972; Salen et al. 1974; Swell et al. 1975). It seems that the period of our 
dosing was short enough to induce satisfactory effects of both stimulation and feedback. Our researches of the optimum dose of CDCA in a short period revealed that $250 \mathrm{mg} /$ day is too small and $750 \mathrm{mg} /$ day too large in amount, and the most effective dose per $\mathrm{kg}$ of body weight probably lies within a range from 5 to $12 \mathrm{mg}$ $/ \mathrm{kg}$. However, the effects of CDCA administration on bile components appear to be influenced not only by its dose but also by its dosing duration. Ono et al. (1976) showed that the treatment with a CDCA dose of $500 \mathrm{mg} /$ day for less than one year apparently had favorable effect on patients with radiolucent round gallstones $1 \mathrm{~cm}$ in diameter each. Their effective dose of CDCA agrees to ours. On the other hand, according to the review by Hofmann and Paumgartner (1974) for Western cases, the radiographic evidence of gallstone disappearance was noted by Back in one of 4 cases of a daily dose of $1.0 \mathrm{~g}$ for 6 months, by Beker in 2 of 5 cases of $0.75 \mathrm{~g}$ to $1.0 \mathrm{~g}$ for 6 months, by Bode in 2 of 6 cases of $1.0 \mathrm{~g}$ to $2.0 \mathrm{~g}$ for 6 months, and by Dowing in 5 of 23 cases of $0.5 \mathrm{~g}$ to $1.5 \mathrm{~g}$ for 12 months. These figures suggest that effective doses of CDCA are larger in Western than in Japanese cases. But in a recent review of the reports on gallstone dissolution with CDCA administration, Bell (1974) suggested, in agreement with our view, that CDCA doses ranging from 5 to $10 \mathrm{mg} / \mathrm{kg}$ will probably be most appropriate in dissolving cholesterol. The difference in apropriate dose of CDCA between Western and Japanese cases may be due to the difference in body weight between them.

It is generally pointed out that side-effects of CDCA administration are diarrhea, nausea, vomiting, anorexia, and hepatic dysfunction, especially elevation. in the levels of SGOT and alkaline phosphatase. No signs of hepatic dysfunction as a side-effect were found in cases of $250 \mathrm{mg} /$ day, but a transient elevation of SGOT and SGPT values was observed in one case of $750 \mathrm{mg} /$ day. But in our cases the administration period was only one week which was too short to advance any definite view of side effects of CDCA administration.

As for side-effects of CDCA in long-term administration, Danzinger et al. (1972) noted diarrhea occurring in all their cases of $4.5 \mathrm{~g} /$ day, accompanying slight increases in levels of SGOT and alkaline phosphatase, but no other hepatic dysfunctions were detected by thorough examinations including liver biopsy. Mok et al. (1974) administered CDCA to cholelithiasis patients in doses of $250 \mathrm{mg}$, $500 \mathrm{mg}, 750 \mathrm{mg}$, and $1,000 \mathrm{mg} /$ day, and found diarrhea occurring in $40 \%$ of cases of $750 \mathrm{mg}$ and $1,000 \mathrm{mg}$, accompanying a slight elevation in level of SGOT, but other hepatic functions were normal. Mok and his co-workers commented that side-effects including diarrhea did not occur in doses ranging from 500 to $750 \mathrm{mg}$, and that even $1,500 \mathrm{mg}$ of CDCA probably would not extend any adverse effect on hepatic functions. Thistle and Hofmann (1973) administered CDCA to 57 cases of gallstone in a dose of $750 \mathrm{mg} /$ day for one month and thereafter increased the dose until diarrhea occurred, then the dose was reduced to $250 \mathrm{mg} /$ day (mean, $18 \mathrm{mg}$ / $\mathrm{kg}$ ). As a result, they found that hepatic function was generally normal in the patients except a slight elevation of SGOT level within a normal range. Liver biopsy performed in 8 cases detected slight pathological changes in 3 of them, but 
the authors commented that whether or not the hepatic changes were due to CDCA administration remained uncertain because of the absence of liver biopsy before the administration. Iser et al. (1975), administering CDCA to 75 cases of cholecystolithiasis in doses from 250 to $1,500 \mathrm{mg}$, found a resultant diarrhea in $49 \%$ of cases of $1,000 \mathrm{mg}$ or more, and in $28 \%$ of those of $750 \mathrm{mg}$ or less; when the doses were reduced to $250 \mathrm{mg}$, no diarrhea appeared. Their report also showed that the rising level of SGOT in cases of CDCA administration remained within a normal range, and that liver biopsy detected no hepatic dysfunctions in these patients. Bell et al. (1974) administered CDCA to 25 patients with gallstone in doses of 0.5 to $1.5 \mathrm{~g}$ ( 7 to $20 \mathrm{mg} / \mathrm{kg}$ ), and in 6 months neither increases in SGOT level nor any other hepatic dysfunctions were found, and liver biopsy revealed no histological differences between cases with and without CDCA administration. As a result, Bell and his colleagues concluded that the administration of CDCA in doses ranging 0.5 to $1.5 \mathrm{~g}$ will not cause any hepatic damage in human cases.

Many reports show that diarrhea and elevation of SGOT level as main sideeffects of CDCA administration are likely to occur in cases of doses over $750 \mathrm{mg} /$ day, diarrhea can be controlled by reducing the dose, and the elevation of SGOT level generally remains within a normal range, suggesting no appreciable influence on liver histology. As a conclusion, it can be stated that our optimum dose of oral CDCA would not cause any adverse side-effect.

\section{Acknowledgment}

We thank to Prof. Z. Yosizawa, Department of Biochemistry, Tohoku University School of Medicine, for his advice.

\section{References}

1) Bartlett, R.G. (1959) Phosphorus assay in column chromatography. J. biol. Chem., 234, $466-468$.

2) Bell, G.D. (1974) The present position concerning gallstone dissolution. Gut, 15, 913929.

3) Bell, G.D., Mok, H.X.I., Thwe, M., Murphy, G.M., Henry, K. \& Dowling, R.H. (1974) Liver structure and function in cholelithiasis: Effect of chenodeoxycholic acid. Gut, 15, 165-172.

4) Danzinger, R.G., Hofman, A.F., Schoenfeld, L.J. \& Thistle, J.L. (1972) Dissolution of cholesterol gallstones by chenodeoxycholic acid. New Engl. J. Med., 286, 1-8.

5) Hofmann, A.F. \& Paumgartner, G. (1974) Chenodeoxycholic Acid Therapy of Gallstones. F.K. Schattauer Verlag, Stuttgart-New York.

6) Isakson, B. (1953) On the lipid constituents of bile from human gallbladder containing cholesterol gallstone. Acta Soc. Med. upsalien., 59, 277-295.

7) Iser, J.H., Dowling, R.H., Mok, H.Y.I. \& Bell, G.D. (1975) Chenodeoxycholic acid treatment of gallstones. New Engl. J. Med., 293, 378-383.

8) Leffler, H.H. \& McDougald, C.H. (1963) Estimation of cholesterol in serum. Amer. J. clin. Path., 39, 311-315.

9) Mok, H.Y.I., Bell, G.D. \& Dowling, R.H. (1974) Effect of different doses of chenodeoxycholic acid on bile-lipid composition and on the frequency of side effects in patients with gallstones. Lancet, 3, 253-257.

10) Ono, T., Ohto, M., Kawamura, K., Saisho, H., Tsuchiya, X., Kimura, K., Yogi, Y., Karasawa, E., Itoh, F., Suzuki, Y., Morita, M., Okuda, K., Nagase, T., Kogure, K., 
Asahina, N., Kumagai, T., Ueno, T., Miki, M., Momose, M. \& Misono, M. (1976) Chenodeoxycholic acid therapy for the dissolution of gallstones. Its efficacy and safety. Jap. J. Gastroenterol., 73, 1232-1246. (Japanese)

11) Salen, G., Tint, G.S., Eliav, B., Deering, N. \& Mosbach, E.H. (1974) Increased formation of ursodeoxycholic acid in patients treated with chenodeoxycholic acid. J. clin. Invest., 53, 612-621.

12) Sandberg, D.H., Sjovall, J., Sjovall, K. \& Turner, D.A. (1965) Measurement of human serum bile acids by gas-liquid chromatography. J. Lipid Res., 6, 182-192.

13) Small, D.M., Dowling, R.H. \& Redinger, R.N. (1972) The enterohepatic circulation of bile salts. Arch. intern. Med., 130, 552-573.

14) Swell, L., Schwartz, C.C., Halloran, L.G. \& Vlahceivc, Z.R (1975) Rapid feedback inhibition of endogenous cholic and chenodeoxycholic acid synthesis by exogenous chenodeoxycholic acid in man. Biochem. biophys. Res. Commun., 64, 1083-1089.

15) Thistle, J.L. \& Hofmann, A.F. (1973) Efficacy and specificity of chenodeoxycholic acid therapy for dissolving gallstones. New Engl. J. Med., 289, 655-659. 